Wright State University

CORE Scholar

$12-2006$

\title{
Fracture of the Scapula with Intrathoracic Penetration in a Skeletally Mature Patient
}

Cary C. Schwartzbach

Hani Seoudi

Amy E. Ross

Kimberly M. Hendershot

Wright State University, kimberly.hendershot@wright.edu

Linda Robinson

See next page for additional authors

Follow this and additional works at: https://corescholar.libraries.wright.edu/surg

Part of the Surgery Commons

\section{Repository Citation}

Schwartzbach, C. C., Seoudi, H., Ross, A. E., Hendershot, K. M., Robinson, L., \& Maekzadeh, A. (2006).

Fracture of the Scapula with Intrathoracic Penetration in a Skeletally Mature Patient. The Journal of Bone and Joint Surgery, 88 (12), 2735-2738.

https://corescholar.libraries.wright.edu/surg/198

This Report is brought to you for free and open access by the Surgery at CORE Scholar. It has been accepted for inclusion in Department of Surgery Faculty Publications by an authorized administrator of CORE Scholar. For more information, please contact library-corescholar@wright.edu. 


\section{Authors}

Cary C. Schwartzbach, Hani Seoudi, Amy E. Ross, Kimberly M. Hendershot, Linda Robinson, and Alireza Maekzadeh

This report is available at CORE Scholar: https://corescholar.libraries.wright.edu/surg/198 


\title{
Fracture of the Scapula With Intrathoracic Penetration in a Skeletally Mature Patient
}

\author{
A CASE REPORT \\ By Cary C. Schwartzbach, MD, Hani Seoudi, MD, Amy E. Ross, MD, \\ Kimberly HENDERSHOT, MD, LINDA ROBINSON, MA, MS, AND ALIREZA MALEKZADEH, MD
}

Investigation performed at Inova Fairfax Hospital, Falls Church, Virginia

$\mathrm{T}$ o our knowledge, intrathoracic displacement of a fractured scapula has only been described in two reports involving adolescents ${ }^{1,2}$. We present the case of a skeletally mature adult with a scapular fracture that penetrated the thoracic cage without causing a pneumothorax. We speculate as to how the adult scapula can deform in a manner consistent with this rare injury. As the patient had advanced Alzheimer disease, the family consented to the publication of data concerning this case.

\section{Case Report}

A seventy-two-year-old woman with Alzheimer disease was A brought to the emergency department at our hospital after being struck by a car while crossing the street. Physical examination revealed deformity of the right tibia and tenderness over the posterior aspect of the left shoulder. There was no evidence of acute respiratory distress or shortness of breath, and the partial oxygen saturation on room air was $98 \%$. Neurovascular examination revealed normal findings in all four extremities. A comminuted midshaft right tibial fracture was diagnosed on plain radiographs. The initial chest radiograph demonstrated multiple left-sided rib fractures without any obvious hemothorax or pneumothorax (Fig. 1). There was suspicion of a left scapular fracture. A computerized tomographic scan of the chest was performed (Figs. 2, 3, and 4). Three-dimensional reconstruction demonstrated a comminuted scapular body and neck fracture. There was an incomplete sagittal split immediately below a transverse fracture that separated the superior and inferior aspects of the scapula (Figs. 3 and 4). The proximal aspect of the lower lateral column was noted to be trapped within the thoracic cage by a displaced, fractured rib (Fig. 2). No evidence of pneumothorax or hemothorax was noted on the computed tomography scan.

The left arm was placed in a sling for comfort. On the second hospital day, the patient underwent uncomplicated closed tibial nailing.

Operative management was recommended for pain control and prevention of long-term pulmonary complications, functional limitations, and anticipated difficulty with late reconstruction should nonoperative management fail. The family equivocated for several days while weighing the risks and benefits of surgical intervention and then consented to surgery, despite the patient's limited ability to participate in any postreconstructive rehabilitation. On the seventh day after the injury, the patient underwent open reduction and internal fixation of the left scapula through a Judet posterior approach $^{3}$. She was sedated, intubated, and ventilated. With the patient placed midway between a lateral decubitus position and a prone position, an inverted L-shaped incision was made along the medial border of the scapula and then laterally along the scapular spine.

The Judet approach was chosen because it allowed more options for fixation. The deltoid origin along the scapular spine

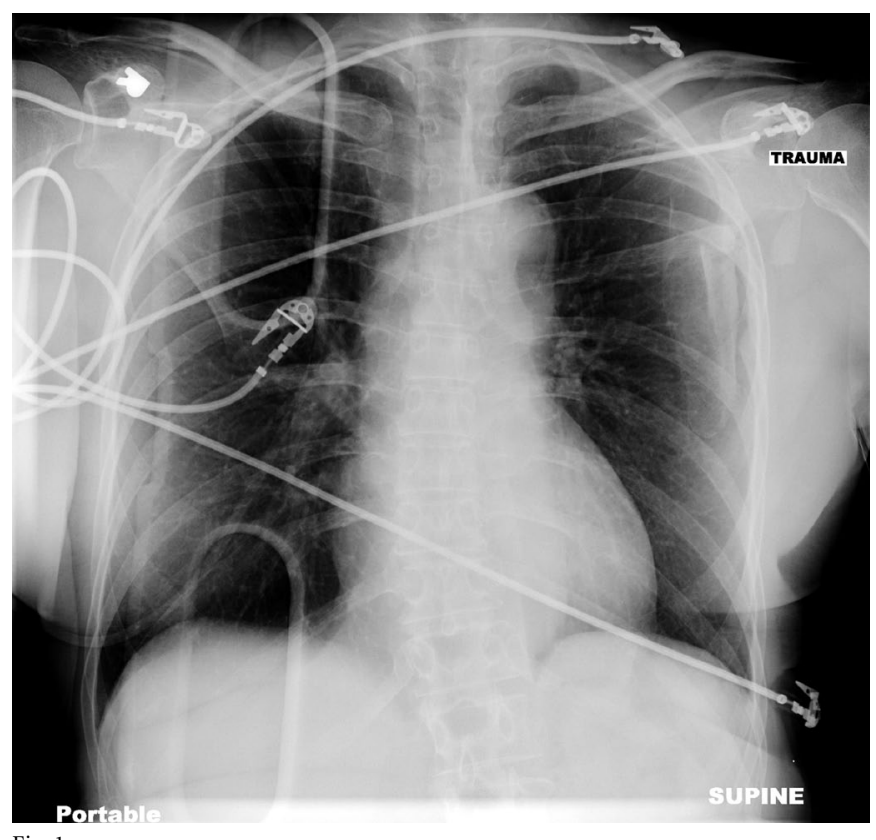

Fig. 1

Anteroposterior radiograph of the chest, demonstrating left rib fractures and a left scapular fracture. 
The Journal of Bone \& JOINT Surgery · JBJS.org Volume 88-A · Number 12 - DeCEMber 2006
Fracture of the Scapula With Intrathoracic Penetration in a Skeletally Mature Patient

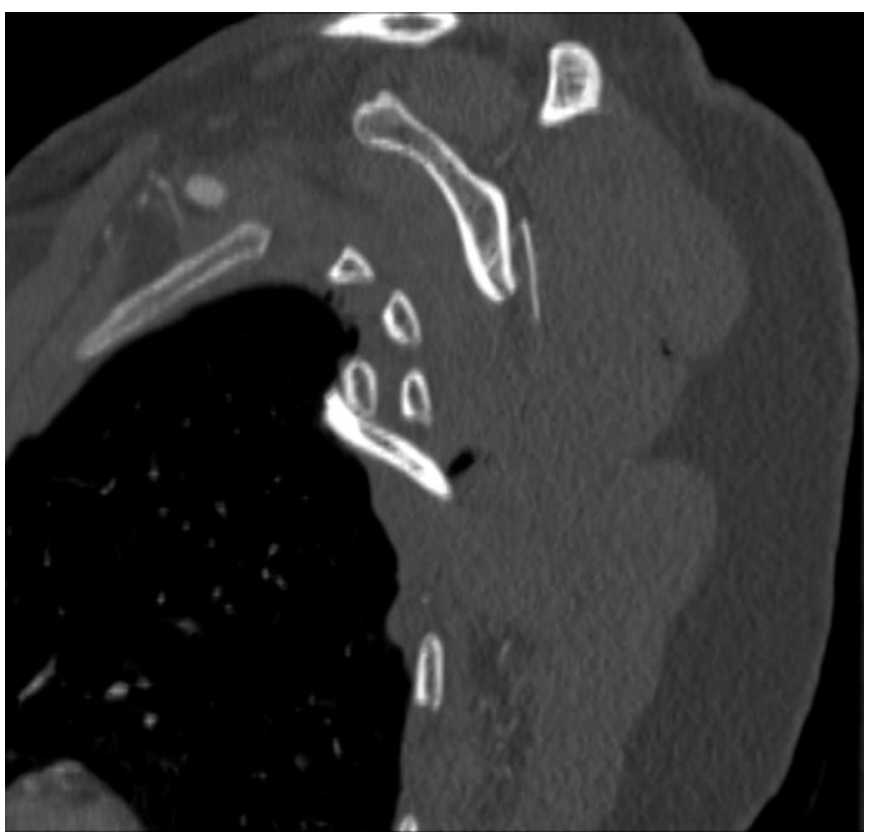

Fig. 2

Two-dimensional computed tomography scan demonstrating intrathoracic penetration by a scapular fracture fragment.

was minimally released and the infraspinatus was turned back on its neurovascular pedicle. The entrapped lateral column could not be freed until the soft tissue over the rib was released. The intrathoracic fracture fragment had penetrated the thoracic cavity through a segmental rib fracture and was locked on the anterior surface of the more inferior rib (Fig. 2).

A chest tube was placed through a separate intercostal space to drain the pleural effusion and any hemothorax that might develop after reduction of the displaced rib. The osseous fragments were then reduced under direct visualization with fluoroscopic assistance and were fixed in a medial-inferior to lateral-inferior fashion. Medially, a twelve-hole straight reconstruction plate was bent into an $\mathrm{L}$ shape so that it could be secured along both the scapular spine and the medial border. Laterally, a curved six-hole pelvic reconstruction plate was secured with bicortical screws. The central part of the scapular body was thin and recessed. Anatomic reduction and fixation was obtained with use of a buttress one-third tubular plate, which was applied over this central fragment and fixed to the reconstruction plates, thereby forming an H-type construct (Fig. 5). The rib returned to its normal anatomic position when released from the scapula. The arm could then be put through a full range of motion without difficulty. On the third postoperative day the chest tube was removed, and two days later the patient was released to a rehabilitation hospital. At the three-month follow-up visit, the patient demonstrated full range of motion and strength of the left arm and shoulder. Radiographs demonstrated adequate alignment of the scapula but union of the fracture was difficult to assess (Figs. 6-A and 6-B). No additional follow-up has occurred as of the time of writing.

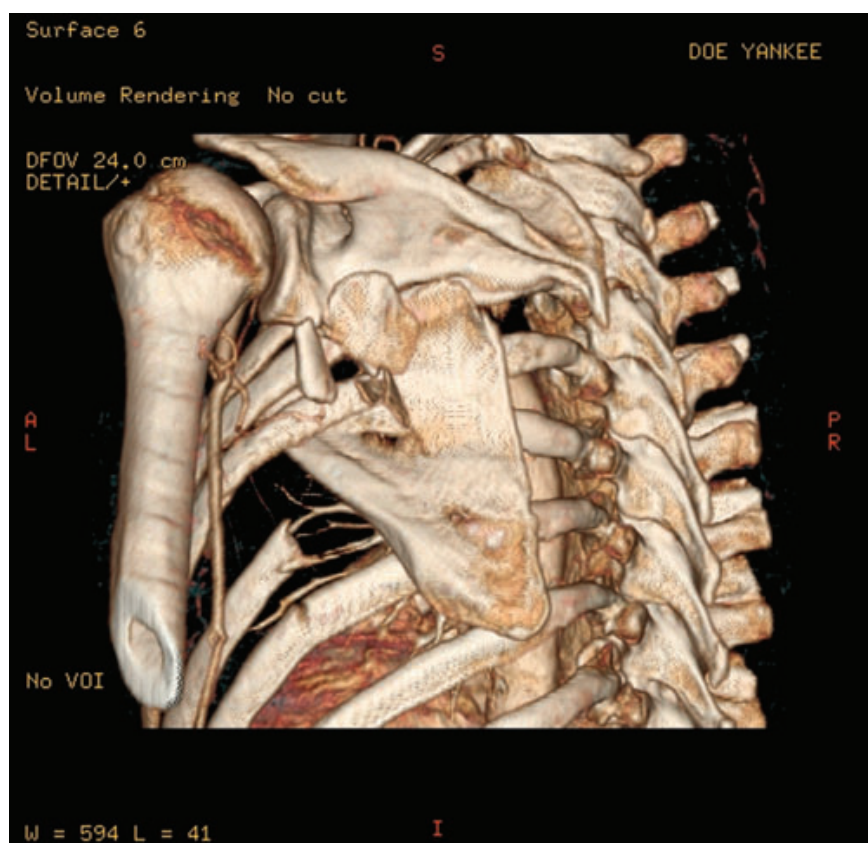

Fig. 3

Three-dimensional reconstruction (posterior view) demonstrating intrathoracic penetration of the scapular fragment.

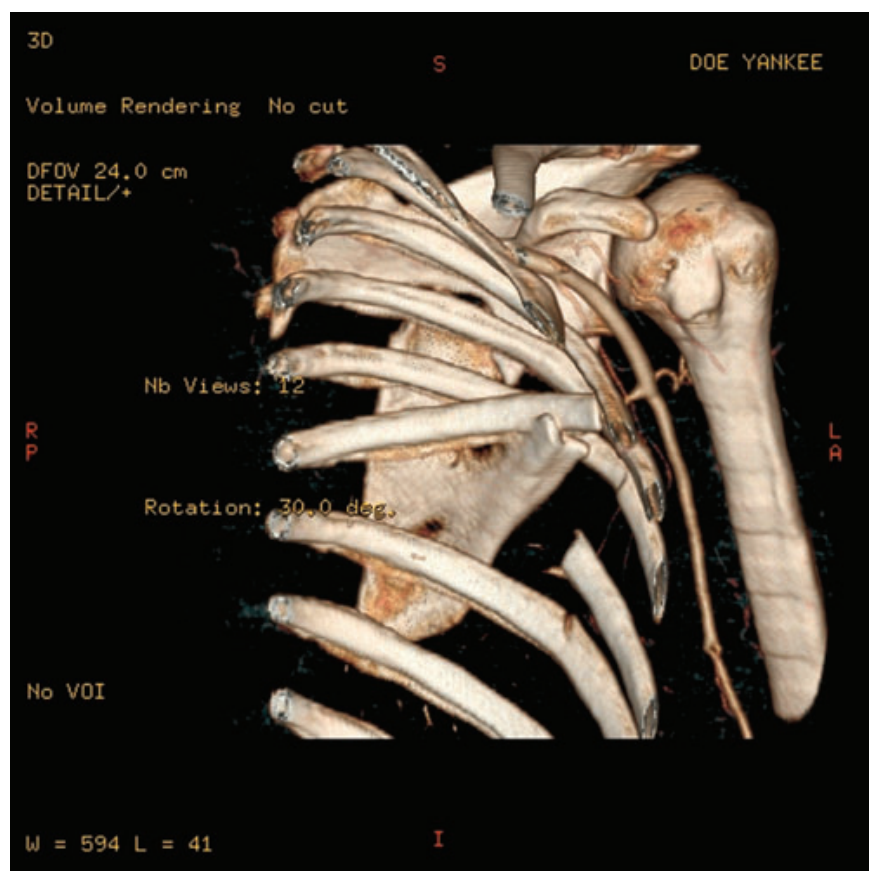
Fig. 4

Three-dimensional reconstruction (anterior view) with chest contents removed, demonstrating entrapment of the scapula by the displaced fractured rib.

\section{Discussion}

W ell protected by the chest wall and the muscles of the Whoulder girdle, the scapula accounts for only $1 \%$ of all fractures ${ }^{4}$. The majority of fractures of the scapular body oc- 
The Journal of Bone \& JOINT Surgery · JBJS.org Volume 88-A · Number 12 - DeCember 2006

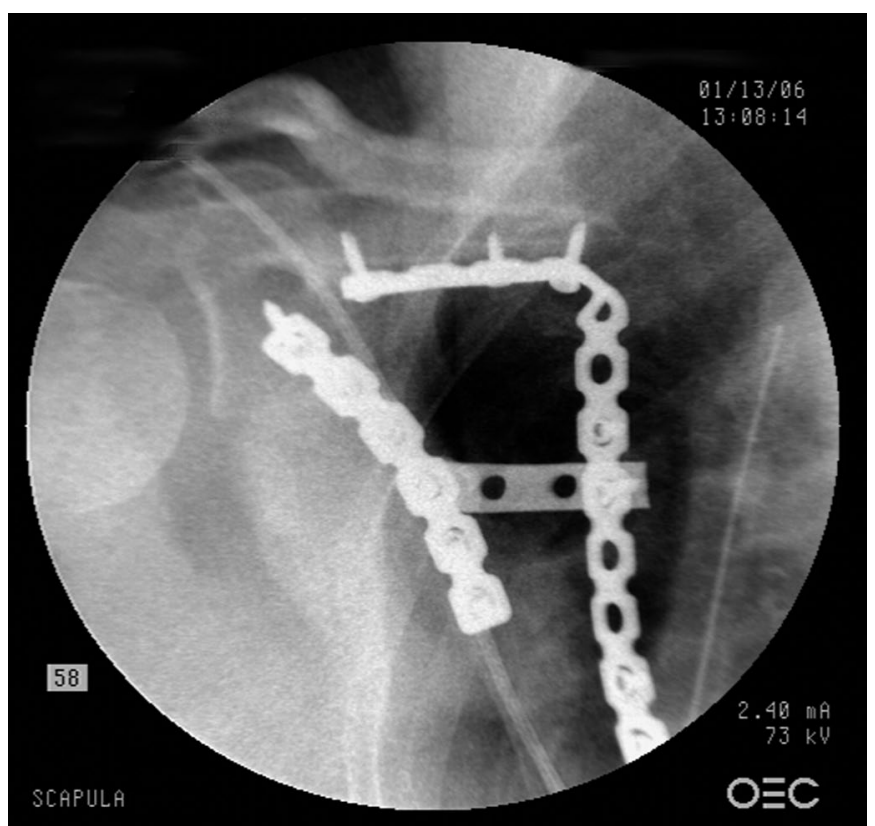

Fig. 5

Postoperative fluoroscopic view of the reconstruction.

cur in association with high-energy accidents that result in multiple injuries ${ }^{5,6}$. The most common associated injury is ipsilateral rib fracture (or fractures) with hemopneumothorax ${ }^{7}$. In none of the previously reported series was the hemopneumothorax caused by a penetrating scapular fragment ${ }^{6-8}$.

Nettrour et al. ${ }^{1}$ reported on an adolescent patient who
Fracture of the Scapula With Intrathoracic Penetration in a Skeletally Mature Patient

presented with an intrathoracic dislocation of the inferior tip of the scapula. Those authors were of the opinion that the injury could only happen in a patient with a nonfractured scapula. Blue et al. ${ }^{2}$ reported on an adolescent patient with intrathoracic displacement of a scapular fracture. Interestingly, the case of our patient was quite similar, with the proximal end of the lower lateral column being entrapped within the thoracic cage. Those authors postulated that it was the plasticity of the adolescent bone that allowed the injury to occur.

It is our opinion that the flat nature of the scapula provides the structural basis for this injury. In our patient, the primary injury was a transverse scapular body fracture that separated the superior and inferior portions of the scapula. As the scapula was subjected to further direct force, it created both a rib fracture and an incomplete sagittal fracture of the inferior fragment. The thick inferior corner of the scapula prevented completion of the fracture line and the medial and lateral columns were free to pivot or twist on each other, analogous to the findings in the case report by Blue et al. ${ }^{2}$. The lateral column continued to displace anteriorly, pushing the fractured rib anteriorly and superiorly, until it was entrapped behind that rib. Pivoting on the intact inferior corner rather than translating anteriorly accounted for this entrapment and may also explain the absence of a pneumothorax. It is the juxtaposition of the thin bone of the central body of the scapula with the much thicker peripheral cortical bone that allows for the incomplete fractures required for this rare sequence of events. The flat bone tears more than breaks and is allowed to twist on itself instead of merely displacing. .

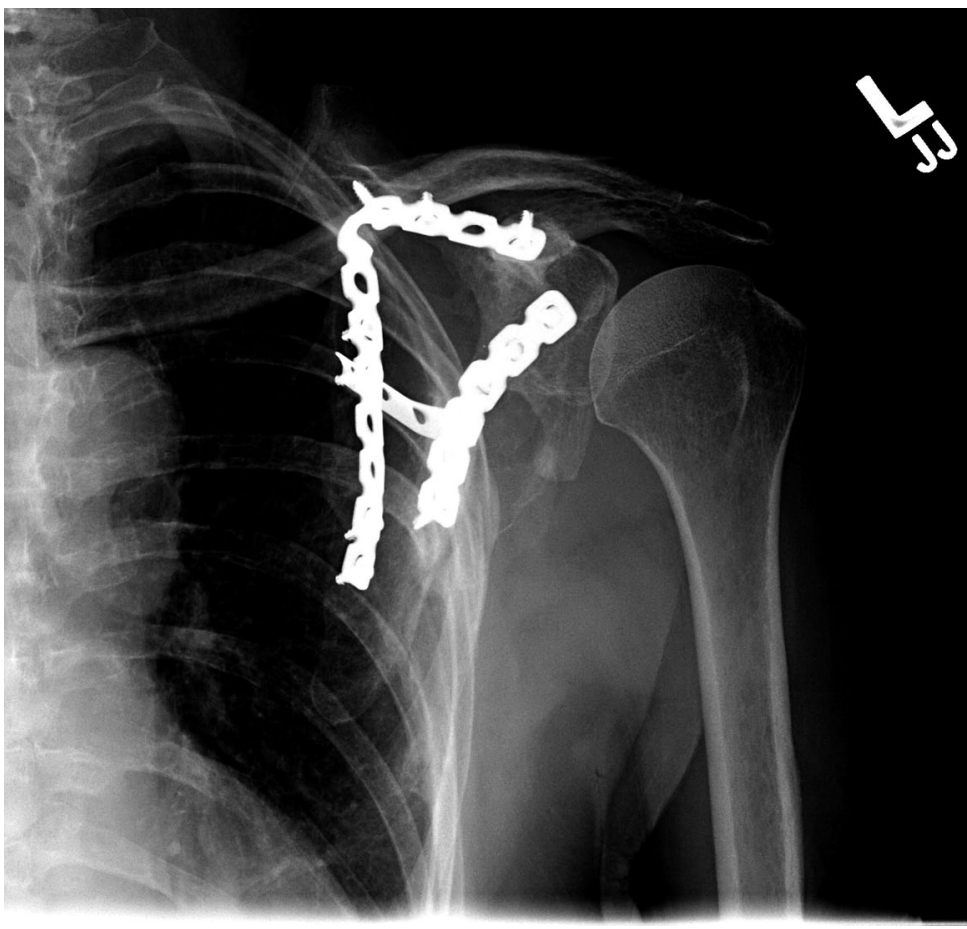

Fig. 6-A

Follow-up radiographs made three months postoperatively.

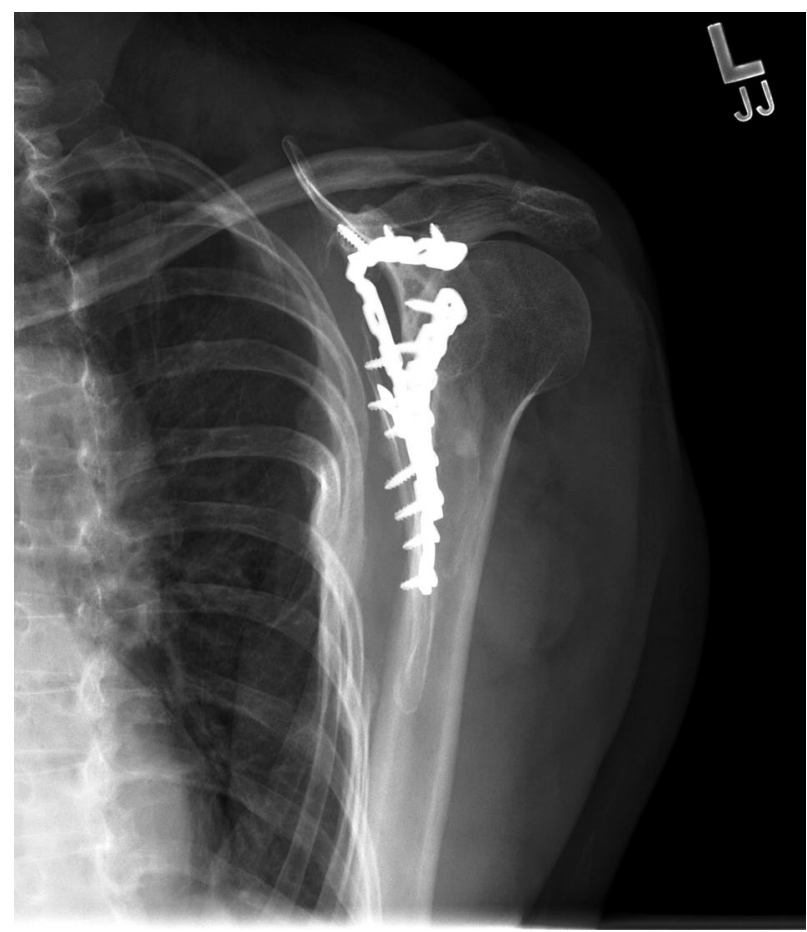

Fig. 6-B 
The Journal of Bone \& JOINT SuRgery - JBJS.org Volume 88-A · Number 12 - DeCember 2006

Cary C. Schwartzbach, MD

Alireza Malekzadeh, MD

8503 Arlington Boulevard, 200, Fairfax, VA 22031

Hani Seoudi, MD

Kimberly Hendershot, MD

Linda Robinson, MA, MS

Inova Fairfax Hospital, 3300 Gallows Avenue, Falls Church, VA 22042. Email address for L. Robinson: Linda.robinson@inova.com

Amy E. Ross, MD

Walter Reed Army Medical Center (WRAMC), 6900 Georgia Avenue, Northwest, Washington, DC 20307
Fracture of the SCapula with Intrathoracic Penetration in a Skeletally Mature Patient

The authors did not receive grants or outside funding in support of their research for or preparation of this manuscript. They did not receive payments or other benefits or a commitment or agreement to provide such benefits from a commercial entity. No commercial entity paid or directed, or agreed to pay or direct, any benefits to any research fund, foundation, educational institution, or other charitable or nonprofit organization with which the authors are affiliated or associated.

doi:10.2106/JBJS.F.00516

\section{References}

1. Nettrour LF, Krufky EL, Mueller RE, Raycroft JF. Locked scapula: intrathoracic dislocation of the inferior angle. A case report. J Bone and Joint Surg Am. 1972; 54:413-6.

2. Blue JM, Anglen JO, Helikson MA. Fracture of the scapula with intrathoracic penetration. A case report. J Bone and Joint Surg Am. 1997;79:1076-8.

3. Miller ME, Ada JR. Injuries to the shoulder girdle. In: Browner BD, Jupiter JB, Levine AM, Trafton PG, editors. Skeletal trauma: fractures, dislocations, ligamentous injuries. Vol 2. Philadelphia: WB Saunders; 1992. p 1291-310.

4. Goss TP. Scapular fractures and dislocations: diagnosis and treatment.
J Am Acad Orthop Surg. 1995:3:22-33.

5. Thompson DA, Flynn TC, Miller PW, Fischer RP. The significance of scapular fractures. J Trauma. 1985;25:974-7.

6. Wilber MC, Evans EB. Fractures of the scapula. An analysis of forty cases and a review of the literature. J Bone Joint Surg Am. 1977;59:358-62.

7. Imatani RJ. Fractures of the scapula: a review of 53 fractures. J Trauma. 1975;15:473-8.

8. Armstrong CP, Van der Spuy J. The fractured scapula: importance and management based on a series of 62 patients. Injury. 1984;15:324-9. 